\title{
Landing Global Industry in the City
}

MARIE ADAMS

Northeastern University
DAN ADAMS

Northeastern University
The goods of global resource industries pass through the post-industrial city in the form of piles, pipelines, tanks, and silos. Gravel, salt, sand, cobbles, and scrap metal are some of the materials fundamental to making and maintaining the urban environment, but their physical and operational relationship to the city is largely unconsidered beyond conventional single-use zoning practices that simply isolate such resource industries from so-called incompatible uses.

This project questions the absence of designed negotiation between the flows of these global industries and the local places where they land, and proposes a series of design strategies that engage the unique physical and operational dimensions of industries and industrial landscapes within cities.

The strategies proposed here were developed and tested through an ongoing project called the PORT at Rock Chapel Marine in Boston Harbor. This project is the designed transformation of a 13 million gallon asphalt tank farm into a shared-use industrial salt dock and public access landscape, where the operations of the industry are synchronized with public recreation and the everyday life of the city. Today, this is the site of a 100,000 ton kinetic salt pile across the street from one of New England's densest residential neighborhoods and the sole point of public access within the industrial waterfront of Chelsea, Massachusetts - at the margin of the global infrastructure of the sea and the local fabric of the city. 


\section{LANDING GLOBAL INDUSTRY IN THE CITY}

This project questions the absence of designed negotiation between the flows of global industries and the local places where they land, and proposes a series of design strategies that engage the unique physical and operational dimensions of industries within cities.

The strategies proposed below were developed and tested through an ongoing project called the PORT at Rock Chapel Marine, in Boston Harbor. This project is the designed transformation of

a 13 million gallon oil tank farm into a shared-use industrial salt dock and public access landscape, where the operations of the industry are synchronized with the everyday life of the city.

Today, this is the site of a 100,000 ton salt pile across the street from one of New England's eighborhoods and the sole point of public access within the industrial waterfront of Chelsea, Massachusetts - at the margin of the global infrastructure of the sea and the local fabric of the city.
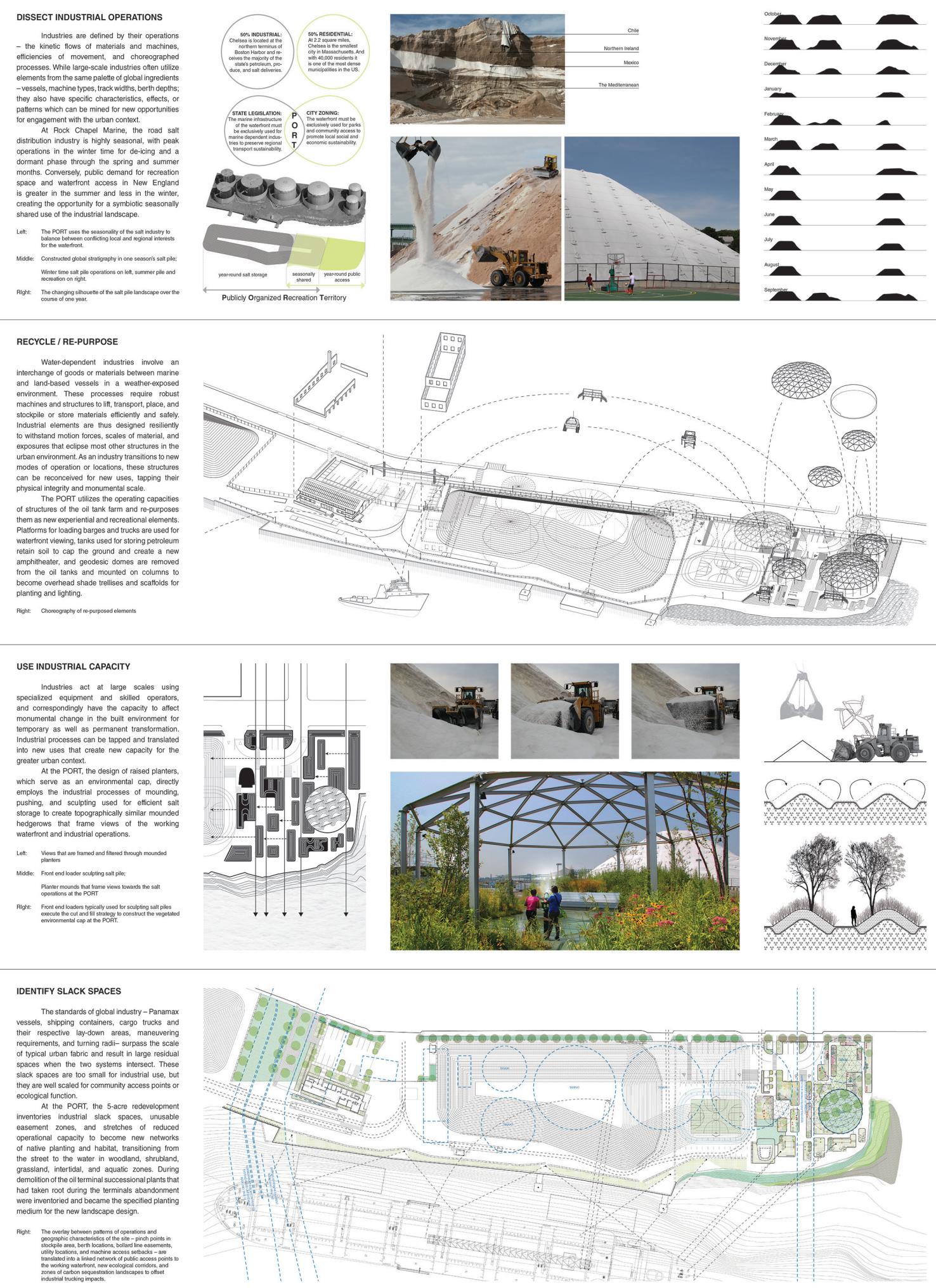